\title{
Impact of history of periodontitis on gene expression of bone-related factors in young patients
}

\author{
Fabiano Ribeiro CIRANO(a) iD \\ Suzana Peres PIMENTEL(a) iD \\ Fernanda Vieira RIBEIRO(a) iD \\ Marcio Zaffalon CASATI(a) \\ Renato Corrêa CASARIN(b) iD \\ Daniel Freire GALLAFASSI(a) iD \\ Denise NISHII(a) ID \\ Mônica Grazieli CORRÊA(a) \\ (a) Universidade Paulista - UNIP, School of \\ Dentistry, Dental Research Division, São \\ Paulo, SP, Brazil. \\ (b) Universidade Estadual de Campinas - \\ Unicamp, School of Dentistry at Piracicaba, \\ Department of Prosthodontics and \\ Periodontics, Piracicaba, SP, Brazil.
}

Declaration of Interests: The authors certify that they have no commercial or associative interest that represents a conflict of interest in connection with the manuscript.

Corresponding Author:

Monica Grazieli Corrêa

E-mail: monica.grazieli@hotmail.com

https://doi.org/10.1590/1807-3107bor-2020.vol34.0014

Submitted: December 13, 2018

Accepted for publication: November 11, 2019

Last revision: January 23, 2020

\begin{abstract}
Although dental implants and bone regenerative procedures are important approaches for the reestablishment of esthetics and function in young patients with a history of generalized aggressive periodontitis (GAP), no predictable outcomes have been reported, and the host osteo-immunoinflammatory response may play a relevant role in this context. In view of the lack of molecular investigations into the bone tissue condition of young patients with periodontitis, the aim of this study was to evaluate the gene expression of bone-related factors in this population. Bone biopsies were obtained from the posterior mandible in 16 individuals previously diagnosed with GAP and on periodontal support therapy and from 17 periodontally healthy $(\mathrm{PH})$ patients. The gene expression of tumor necrosis factor (TNF)- $\alpha$, transforming growth factor (TGF)- $\beta$, receptor activator of the NF- $\kappa B$ ligand (RANKL), osteoprotegerin (OPG), osteocalcin (OC), bone sialoprotein (BSP), and type I collagen (COL-I), important biomarkers of bone turnover, was evaluated by qRT-PCR. Lower TGF- $\beta$ and OPG mRNA levels were observed in GAP patients compared to PH individuals ( $\mathrm{p} \leq 0.05)$. There were no between-group differences in levels of TNF- $\alpha$, BSP, RANKL, OC, or COL-I mRNA ( $p>0.05)$. In young adults, a history of periodontal disease can negatively modulate the gene expression of important bone-related factors in alveolar bone tissue. These molecular outcomes may contribute to the future development of therapeutic approaches to benefit bone healing in young patients with history of periodontitis via modulation of osteo-immuno-inflammatory biomarkers.
\end{abstract}

Keywords: Dental Implants; Biomarkers; Gene Expression; Bone and Bones; Aggressive Periodontitis; Osseointegration.

\section{Introduction}

Generalized aggressive periodontitis (GAP), previously classified as early-onset periodontitis, ${ }^{1}$ is a destructive periodontal disease that develops early in life, usually in young adults (onset before 35 years of age), and promotes severe clinical attachment loss and bone destruction. ${ }^{2,3}$ Early tooth loss is one of the consequences of this aggressive disease; thus, dental implants - combined in some cases with bone regenerative procedures are a mainstay of the reestablishment of esthetics and function in young patients with a history of periodontal disease. 
Although dental-implant rehabilitation has been reported as safe and successful in the general population, ${ }^{4}$ some factors can interfere in the predictability of the dental implant outcomes, ${ }^{5}$ including history of periodontitis. ${ }^{6,7}$

History of periodontitis, especially aggressive periodontitis, is a risk factor for the long-term survival of dental implants. ${ }^{6,8}$ Monje et al. ${ }^{9}$ showed that the risk ratio for dental implant failure in patients with a history of GAP was significantly higher than in healthy patients (4.0) and in those with chronic periodontitis (3.97), which is consistent with recently published data. ${ }^{10}$ In a prospective 10 -year study, implants placed in patients with GAP exhibited continuous bone loss and attachment loss, and the survival rate $(83 \%)$ was lower than in periodontally healthy subjects $(100 \%){ }^{11}$ The impaired bone performance of dental implants in patients with aggressive periodontitis is also observed during regenerative procedures; greater attachment loss and bone resorption were detected around implants placed in regenerated bone (guided bone regeneration) than in native bone after 3 years of loading. ${ }^{11}$

The host osteo-immunoinflammatory response seems to play a relevant role in the onset and progression of GAP. Namely, the disease appears to be associated with deficiencies in host defenses and a hyper-responsive inflammatory phenotype, with augmented local and systemic levels of inflammatory mediators. ${ }^{12,13,14}$ This altered host response could explain, at least in part, the higher susceptibility of patients with GAP to mucositis and peri-implantitis. ${ }^{8}$ In addition, it could be hypothesized that impairment of host mediators required for bone repair and maintenance would be associated with the reduced implant survival and success rates observed in patients with aggressive periodontitis. ${ }^{8,9,15}$ However, no study has been conducted to assess this issue, and the precise molecular mechanisms underlying impaired bone alveolar performance in patients with a history of aggressive periodontitis remain unknown.

Thus, the aim of this study was to compare the gene expression of major biomarkers of bone turnover and osteoimmunity - tumor necrosis factor (TNF)- $\alpha$, transforming growth factor (TGF)- $\beta$, receptor activator of the NF- $\mathrm{kB}$ ligand (RANKL), osteoprotegerin (OPG), osteocalcin (OC), bone sialoprotein (BSP), and type I collagen (COL-I) - in alveolar bone biopsy specimens obtained from periodontally healthy patients and from young individuals with a history of periodontitis. Our hypothesis was that an early history of periodontitis in young adults could modulate the expression of these genes in the alveolar bone.

\section{Methodology}

\section{Study design}

This investigation was designed as a parallel, crosssectional, examiner-blind, clinical study. Approval was obtained from ethics committee of Universidade Paulista (UNIP) (protocol no. 28676814.0.0000.5512).

\section{Patient population}

The study population comprised 33 young adults: 16 patients on maintenance therapy for GAP and 17 periodontally healthy $(\mathrm{PH})$ controls (Figure 1). All were recruited among patients referred to the UNIP School of Dentistry between March 2014 and December 2016. Detailed medical records were obtained, and individuals who met the inclusion criteria were invited to participate in the study. All eligible patients were thoroughly informed of the nature and potential risks and benefits of their participation in the study, and all provided written informed consent.

\section{Inclusion and exclusion criteria}

The inclusion criteria were age 15 to 35 years and having a clinical indication for posterior mandibular surgery (third molar extraction, implant rehabilitation, or bone graft). Group-specific criteria also applied: $\mathrm{PH}$ patients should have no probing depth (PD) and clinical attachment level (CAL) $>3 \mathrm{~mm}$, bleeding on probing (BoP) in $<15 \%$ of sites, and no radiographic evidence of horizontal or vertical bone loss (bone crest $>95 \%$ of the proximal tooth sites and $<3 \mathrm{~mm}$ at the cementoenamel junction). ${ }^{16}$ GAP patients should have first molars/incisors with interproximal PD and CAL $>5 \mathrm{~mm}$ on at least two permanent teeth (one of which is a first molar), as well as generalized interproximal PD and CAL $>5 \mathrm{~mm}$ affecting at least three permanent teeth other than first molars and incisors. ${ }^{16,17}$ Patients with a diagnosis of GAP were also required to have received adequate periodontal 


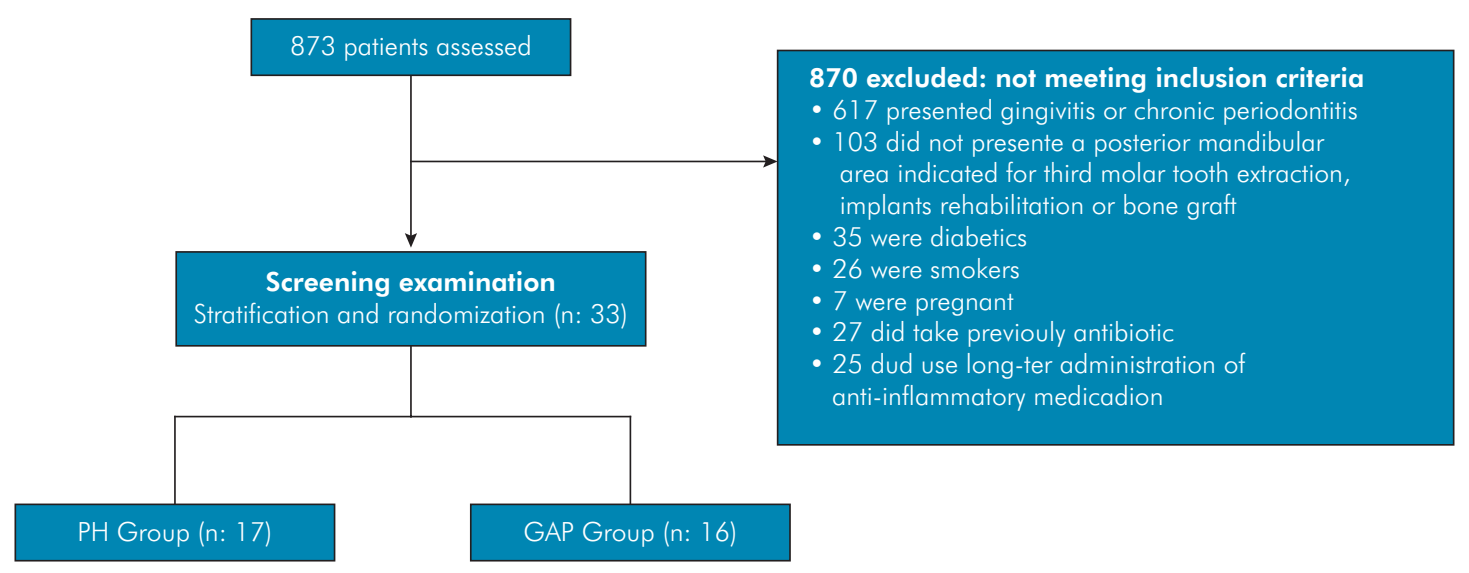

Figure 1. Flow diagram of participant selection.

therapy in the past and be on supportive periodontal therapy (SPT), as described below.

The exclusion criteria were pregnancy, lactation, smoking (current or former), presence of risk factors that could affect expression of the target genes (including osteoporosis, chronic use of immunosuppressive or anti-inflammatory medication, use of bisphosphonates, severe metabolic disease), and a history of previous regenerative procedures in the posterior mandible.

\section{Periodontal treatment protocol}

In the pre-study phase, patients in the GAP group underwent calculus removal, supragingival plaque control, and received provisional restorations as needed. Subgingival debridement was performed in one session using curettes (Gracey, Hu-Friedy, Chicago, USA) and an ultrasonic device (Cavitron, Dentsply, Tulsa, USA), always performed by the same operator (MGC). All patients were enrolled in an SPT program. After 3 months, an intraoral examination was performed, patients underwent surgical procedures as clinically indicated, and bone biopsies were harvested.

\section{Surgical protocol and sample collection}

All surgical procedures were performed by the same operator (DFG). Surgical areas were anesthetized and mucoperiosteal incisions were made in the alveolar ridge mucosa. Bone tissue was collected from the sites designated to receive one of the surgical procedures - third molar tooth extraction, implant rehabilitation, or bone graft - using a bone collector, as described elsewhere. ${ }^{18}$ The specimens were placed in tubes containing RNAlater (Life Technologies, Rockville, USA) and stored at $-70^{\circ} \mathrm{C}$ until subsequent analysis. Postoperative medications consisted of metamizole sodium for analgesia ( $500 \mathrm{mg}$, every $6 \mathrm{~h}$, for 2 days), depending on the surgical procedure, and $0.12 \%$ chlorhexidine mouthwash (every $12 \mathrm{~h}$ for 7 days).

\section{Gene expression analysis}

For gene expression analysis, the mRNA levels of TNF- $\alpha$, OC, TGF- $\beta$, RANKL, OPG, BSP, and COL-I were determined as described elsewhere ${ }^{18}$. Briefly, total RNA was isolated from the biopsy specimens by the Trizol method (Gibco BRL, Life Technologies, USA) according to the manufacturer's recommendation. RNA samples were resuspended in diethyl pyrocarbonate-treated water and their concentration was determined in a NanoDrop 1000 spectrophotometer (NanoDrop Technologies LLC, Wilmington, USA). Total RNA was treated with DNase (Ambion TURBO DNA-free Kit; Life Technologies, Carlsbad, EUA) and $1 \mathrm{mg}$ was used for complementary DNA (cDNA) synthesis. The reaction was carried out using the First-Strand cDNA Synthesis Kit (Roche Diagnostics, Indianapolis, USA). Primers were designed using LightCycler Probe Design Software (Roche Diagnostics $\mathrm{GmbH}$, Mannheim, Germany) (Table 1). The real-time quantitative polymerase chain reaction (qPCR) (LightCycler System; Roche Diagnostics GmbH, Mannheim, Germany) was performed using 
a SYBR Green kit (FastStart DNA Masterplus SYBR Green; Roche Diagnostics Co, Indianapolis, USA). The results were expressed as relative amounts of the target gene, with glyceraldehyde3-phosphate dehydrogenase (GAPDH) as the inner reference gene, using a relative quantification tool (LightCycler 4 software, Roche Diagnostics $\mathrm{GmbH}$, Mannheim, Germany).

\section{Data analysis}

The number of biopsy specimens included in this study was based on previous investigations reporting differences in the levels of mRNA of immune-inflammatory and bone-related genes ${ }^{18}$. All statistical analyses were performed in SAS release 9.3 (SAS Institute, Cary, USA). Data were first examined for normality by the Kolmogorov-Smirnov test; if the assumption was confirmed, parametric tests were used.

The differences in CAL and PD means and age between the two groups were compared using the Student $t$-test; for the other clinical parameters (FMPS and FMBS), the Mann-Whitney test was used. The $\mathrm{c}^{2}$ test was used to detect differences in the distribution of gender and ethnicity. The significance of the differences in mRNA levels between the two groups was compared using the Mann-Whitney test. The level of significance was set at $5 \%$.

\section{Results}

No significant between-group differences were observed for age, gender, or ethnicity ( $p>0.05$; Table 2). Mean PD and CAL and percent FMPS and

Table 1. Primer sequences for each gene, amplification profiles and estimated length of the qPCR product for each gene.

\begin{tabular}{lccc}
\hline Gene & \multicolumn{1}{c}{ Sequence $\left(5^{\prime}-3^{\prime}\right)$} & $\begin{array}{c}\text { Length of Qpcr product }(\mathrm{bp}) \\
\text { CATCCAACCTTCCCAAACG }\end{array}$ & $\begin{array}{c}\text { Amplification profile, temperature } \\
\left({ }^{\circ} \mathrm{C}\right) / \text { time }(\mathrm{s})\end{array}$ \\
\hline TNF- $\alpha$ & GCAACAATTCCTGGCGATAC & 159 & $95 / 10,56 / 5,72 / 6$ \\
TGF- $\beta$ & TACACGACTCAGTATCCATGC & 181 & $95 / 1056 / 10,72 / 7$ \\
RANKL & TCCGGAAACAGTGAATCAACTC & 158 & $95 / 10,56 / 5,72 / 6$ \\
OPG & GTATACAGGGTTAGCTGCAATC & 151 & $95 / 10,56 / 5,72 / 6$ \\
BSP & CCTTTGGTGACTCACCG & 273 & $95 / 10,56 / 5,72 / 11$ \\
OC & CGAAACCTGTATCCGGG & 230 & $95 / 10,56 / 5,72 / 9$ \\
COL-I & CTGAGTACGTCGTGGAGTC & 156 & $95 / 10,56 / 5,72 / 6$ \\
GAPDH & CTG & 187 & $95 / 10,56 / 5,72 / 7$ \\
\hline
\end{tabular}

TN)- $\alpha$ : Tumor necrosis factor; TGF- $\beta$ : transforming growth factor; RANKL: receptor activator of the NF- $\mathrm{kB}$ ligand; OPG: osteoprotegerin; BSP: bone sialoprotein; OC: osteocalcin; COL 1: type I collagen; GAPDH:glyceraldehyde-3-phosphate dehydrogenase.

Table 2. Demographic characteristics of the study population and clinical parameters.

\begin{tabular}{lcc}
\hline Variable & GAP $(n=16)$ & $P H(n=17)$ \\
\hline Characteristics & & $29.82 \pm 5.53$ \\
Age (mean \pm SD, years) & $31.12 \pm 3.10$ & $09 /$ ago \\
Gender (M/F) & $07 /$ set & 52.94 \\
Ethnicity (\% white) & 50 & $3.11 \pm 0.77$ \\
Clinical parameters (mean \pm SD) & $5.10 \pm 0.80^{*}$ & $2.21 \pm 0.69$ \\
CAL (mm) & $4.90 \pm 0.77^{*}$ & $12.50 \pm 4.20$ \\
PD (mm) & $37.32 \pm 12.32^{* *}$ & $11.73 \pm 4.63$ \\
FMPS (\%) & $36.51 \pm 15.07^{* *}$ & \\
FMBS (\%) & & \\
\hline
\end{tabular}

*Represents significant between-group differences by Student's t-test $(p<0.0001)$; ${ }^{*}$ Represents significant between-group differences by the Mann-Whitney test $(p<0.0001) ; S D$ : standard deviation; CAL: clinical attachment level; PD: probing depth; FMPS: full mouth plaque score; FMBS: full mouth bleeding score. 
FMBS were significantly higher in the GAP group compared to the PH group ( $<<0.0001$; Table 2).

Concerning gene expression, significantly higher TGF- $\beta$ mRNA levels were observed in the PH bone biopsies (231.52 \pm 186.52$)$ when compared to GAP specimens $(80.22 \pm 62.29)(p=0.04)$. Additionally, increased gene expression of OPG was detected in PH samples $(4.88 \pm 5.41)$ compared to GAP specimens $(1.41 \pm 2.66 ; p=0.05)$. There was no between-group difference in expression of TNF- $\alpha(1.44 \pm 2.80$ and $1.20 \pm 2.82$ for GAP and PD, respectively; $\mathrm{p}=0.41$ ), BSP $(2.31 \pm 2.47$ and $4.09 \pm 5.12$ for GAP and PD, respectively; $\mathrm{p}=0.33)$, RANKL (3.70 \pm 7.61 and $0.85 \pm 1.10$ for GAP and PD, respectively; $\mathrm{p}=0.18$ ), OC (2.01 \pm 2.83 and $4.28 \pm 5.99$ for GAP and PD, respectively; $\mathrm{p}=0.45)$, or COL-I $(34.29 \pm 44.05$ and $55.03 \pm 76.73$ for GAP and PD, respectively; $p=0.20$ ). Figure 2 shows the gene expression of all markers of interest in the two groups.

\section{Discussion}

Aggressive periodontitis is a severe form of loss of periodontal attachment and bone, leading to early tooth loss and usually affecting young adults. ${ }^{2,3}$ Patients with periodontitis onset before 30 years of age may be more susceptible to loss of marginal soft tissues and bone, which are known determinants of the higher rate of implant failure in this patient population. ${ }^{19}$ The exact molecular mechanisms that could lead to greater impairment of bone repair or maintenance of in individuals with a history of periodontitis compared to patients who have always been periodontally healthy. The present study hypothesized that young patients with a history of periodontitis would display a distinct pattern of bone-related marker expression in alveolar bone as compared to periodontally healthy, age-matched controls, which could explain the different susceptibilities to impaired bone healing and long-term bone preservation around dental implants in these individuals.

Interestingly, we found that TGF- $\beta$ expression was downregulated in alveolar bone specimens from patients with GAP when compared to those obtained from PH individuals ( $\mathrm{p} \leq 0.05$; Figure 2).
TGF- $\beta$ is an important growth factor known to participate in the formation of several tissues through production of extracellular proteins, regulation of matrix metalloproteinases, and proliferation of fibroblasts during the wound healing process, including in bone. ${ }^{20,21,22}$ TGF- $\beta$ may be involved in callus formation, osteoclast apoptosis, and inhibition of osteoclast activation. ${ }^{20,23,24}$ Produced by platelets, chondrocytes and osteoblasts, TGF- $\beta$ is released during bone turnover and regeneration, and can be deposited in the bone matrix, where it stimulates proliferation of mesenchymal stem cells, preosteoblasts, chondrocytes, and osteoblasts. ${ }^{20,24}$ The reduced mRNA level of TGF- $\beta$ observed in the present study in patients with aggressive periodontitis is consistent with previous findings suggesting that high TGF- $\beta$ production may be a protective factor for periodontitis, accelerating connective tissue remodeling and angiogenesis, which could contribute to inflammatory regulation and/or to bone remodeling events. ${ }^{25,26}$ Interestingly, in the current investigation there was a trend towards downregulation of both OC and BSP in the bone tissue of GAP patients, which may be an additional indication of the role of aggressive periodontitis in osteoclastogenesis, since both of these markers are involved in regulation of osteoblast function, bone turnover, and mineralization. ${ }^{27,28}$

In accordance with these findings, our qRTPCR analysis also demonstrated that OPG mRNA levels were downregulated in bone tissue of GAP patients when compared to healthy controls ( $p \leq 0.05$; Figure 2). Both RANKL and OPG play critical roles not only in maintaining bone homeostasis, but also in controlling bone healing. ${ }^{29}$ In this context, OPG exerts an important function of protecting the skull from bone resorption by binding to RANKL and blocking the RANK/RANKL interaction, thus inhibiting osteoclast differentiation. ${ }^{29,30}$ The results of the present study therefore suggest that OPG expression in alveolar bone tissue is negatively modulated in young adults with a history of aggressive periodontitis, which could predispose these patients to impaired bone homeostasis and higher susceptibility to implant failure and lower implant success/survival rates. Although no significant between-group difference 
A

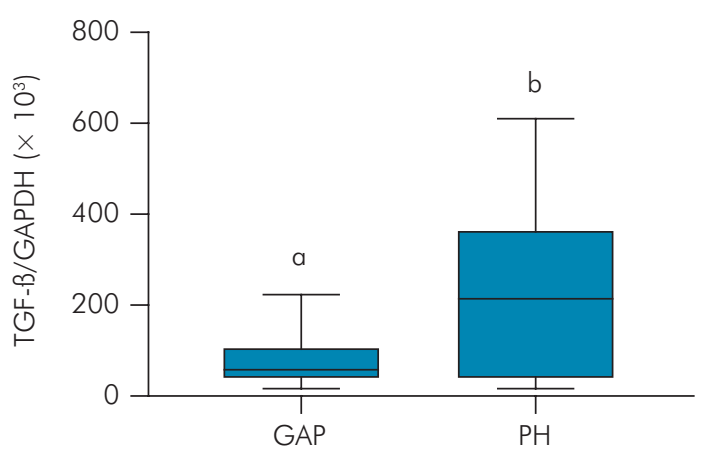

C

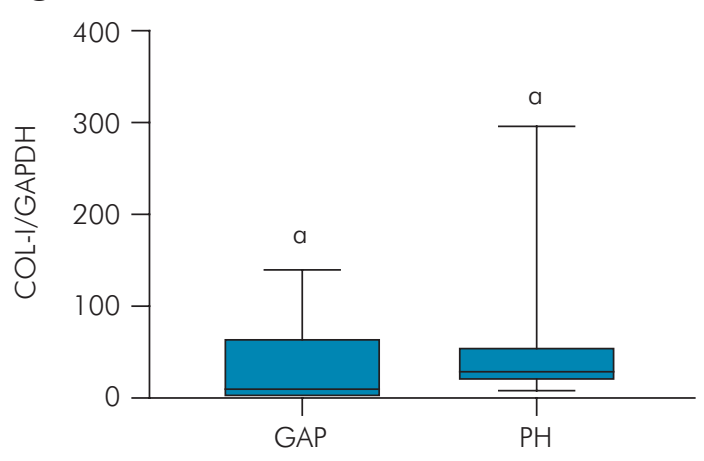

$\mathbf{E}$

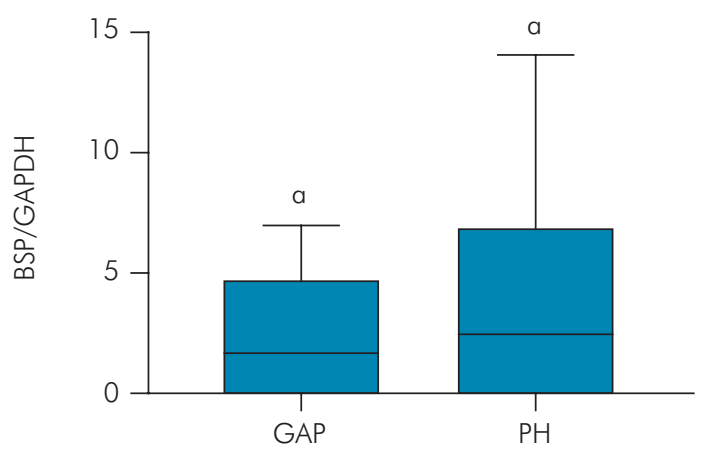

G

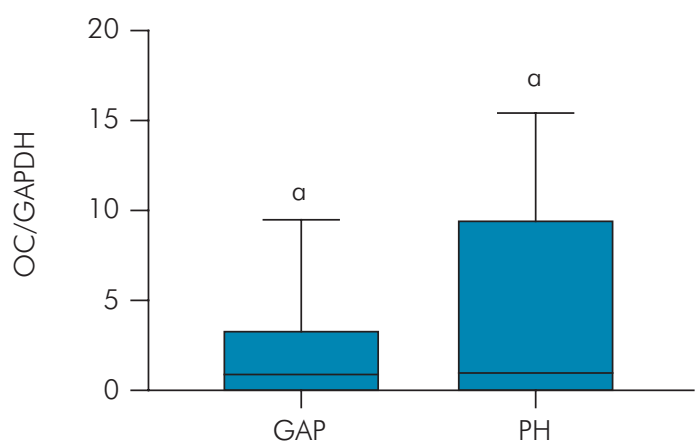

B

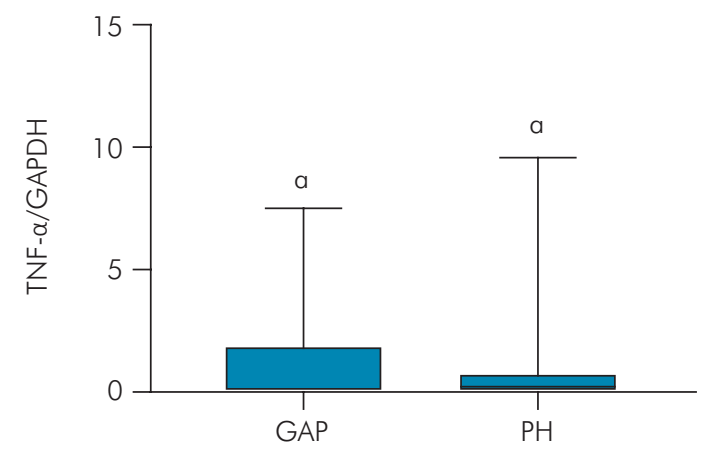

D

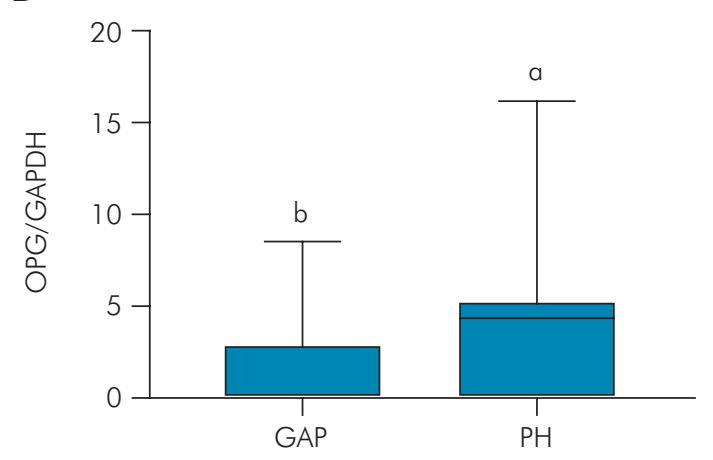

$\mathbf{F}$

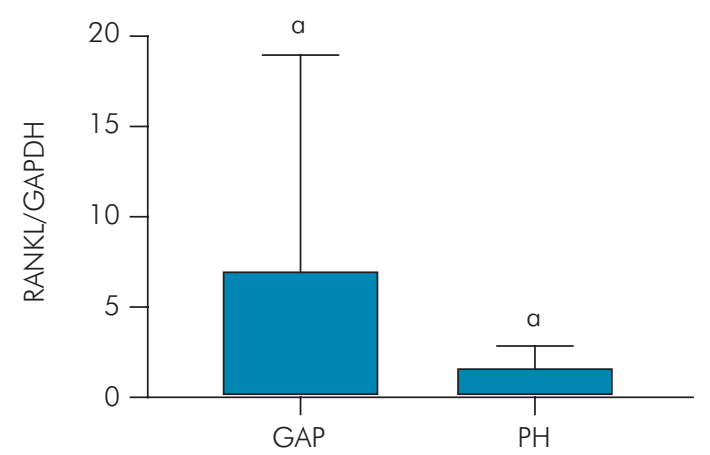

Figure 2. Box plot analysis of gene expression (mRNA of target gene/GAPDH) for the generalized aggressive periodontitis and periodontally healthy groups. Different letters indicate significant differences between groups (Mann-Whitney test; $p<0.05)$. (A) Transforming growth factor (TGF)- $\beta$; (B) Tumor necrosis factor (TNF)- $\alpha$; (C) Type I collagen (COL I); (D) Osteoprotegerin (OPG); (E) Bone sialoprotein (BSP); (F) Receptor activator of the NF-אB ligand (RANKL); (G) Osteocalcin (OC), glyceraldehyde-3-phosphate dehydrogenase (GAPDH). 
was observed in levels of RANKL, a trend towards increased expression of this molecule in specimens from GAP patients when compared to healthy controls corroborates this hypothesis, suggesting a harmful role of aggressive periodontitis in alveolar bone tissue. Previous studies have demonstrated an elevated level of RANKL expression and a reduced level of OPG expression in periodontally affected gingival tissues as compared with healthy gingival tissues. ${ }^{31}$ While a positive association of RANK and OPG has been described with bone-destructive diseases, such as Paget's disease of bone ${ }^{32}$ and osteoporosis, ${ }^{33}$ RANK/RANKL/OPG gene polymorphisms have no strong association with the pathogenesis of aggressive periodontitis. ${ }^{34}$ Although some studies have investigated the relationship of GAP with local modulation of the RANK/RANKL/OPG cascade in biopsies from diseased gingival tissue or from gingival crevicular fluid, $, 35,36,37,38$ data regarding the modulation of these markers in alveolar bone tissue is scarce, and further investigations are required to elucidate the precise cellular and molecular role of GAP in alveolar bone.

It is important to mention that both implant therapy and regenerative bone procedures are therapeutic options both for periodontally healthy persons and for patients successfully treated for periodontitis, although increased rates of biological complications might be expected in GAP patients. ${ }^{8,10}$ In this context, dental implants placed in individuals treated for GAP - even with a strict recall schedule - are at a fivefold risk of failure and 14-fold risk of peri-implantitis when compared to implants placed in periodontally healthy individuals. ${ }^{8}$ Thus, although the presence of biofilm and microorganisms are known risk factor for the pathogenesis of peri-implantitis, ${ }^{39}$ presence of pathogenic bacteria alone did not lead to the destruction of peri-implant tissue; especially in GAP patients, the cause of impaired bone homeostasis can be related to genetic factors ${ }^{34,40}$ and may be associated with negative modulation of the osteoimmune host response, as supported by our findings.

Some limitations of this study should be noted. Only bone tissue was collected during biopsy, as the presence of other tissues could influence the results and interfere with assessment of the bone tissue response, which was the focus of this investigation. However, measurement of the expression of genes of interest in other tissues (periosteum, soft tissue) could provide important additional information. Furthermore, we did not perform protein quantification; molecular assays using real-time PCR for measurement of mRNA levels were used instead. Further studies could be conducted to determine actual protein levels of bonerelated factors in bone biopsy specimens from young adults with a history of periodontitis.

\section{Conclusion}

Collectively, our results support the hypothesis that the balance of bone-related mediators in young adults with periodontitis is shifted towards a state of reduced bone homeostasis, which could be detrimental for bone augmentation procedures, osseointegration, and longterm bone maintenance around future dental implants. The lack of information regarding the molecular mechanisms involving in bone tissue homeostasis in young adults with a history of periodontitis limits discussion of this issue, and additional studies are required to further elucidate the potentially higher risk of biological complications after bone grafting or dental implant placement in this patient population. In future, research into the mutual roles of the skeletal and immune systems at the cellular and molecular levels in GAP may allow development of novel therapeutic approaches to improve bone healing in this patient profile via modulation of osteo-immunoinflammatory biomarkers.

\section{References}

1. Tonetti MS, Mombelli A. Early-onset periodontitis. Ann Periodontol. 1999 Dec;4(1):39-53. https://doi.org/10.1902/annals.1999.4.1.39

2. Nibali L, Farias BC, Vajgel A, Tu YK, Donos N. Tooth loss in aggressive periodontitis: a systematic review. J Dent Res. 2013 Oct;92(10):868-75. https://doi.org/10.1177/0022034513501878 
3. Kulkarni C, Kinane DF. Host response in aggressive periodontitis. Periodontol 2000. 2014 Jun;65(1):79-91. https://doi.org/10.1111/prd.12017

4. Jung RE, Zembic A, Pjetursson BE, Zwahlen M, Thoma DS. Systematic review of the survival rate and the incidence of biological, technical, and aesthetic complications of single crowns on implants reported in longitudinal studies with a mean follow-up of 5 years. Clin Oral Implants Res. 2012 Oct;23 Suppl 6:2-21. https://doi.org/10.1111/j.1600-0501.2012.02547.x

5. Clementini M, Rossetti PH, Penarrocha D, Micarelli C, Bonachela WC, Canullo L. Systemic risk factors for peri-implant bone loss: a systematic review and meta-analysis. Int J Oral Maxillofac Surg. 2014 Mar;43(3):323-34. https://doi.org/10.1016/j.ijom.2013.11.012

6. Wen X, Liu R, Li G, Deng M, Liu L, Zeng XT, et al. History of periodontitis as a risk factor for long-term survival of dental implants: a meta-analysis. Int J Oral Maxillofac Implants. 2014 Nov-Dec;29(6):1271-80. https://doi.org/10.11607/jomi.3544

7. Graetz C, El-Sayed KF, Geiken A, Plaumann A, Sälzer S, Behrens E, et al. Effect of periodontitis history on implant success: a long-term evaluation during supportive periodontal therapy in a university setting. Clin Oral Investig. 2018 Jan;22(1):235-44. https://doi.org/10.1007/s00784-017-2104-4

8. Swierkot K, Lottholz P, Flores-de-Jacoby L, Mengel R. Mucositis, peri-implantitis, implant success, and survival of implants in patients with treated generalized aggressive periodontitis: 3- to 16-year results of a prospective long-term cohort study. J Periodontol. 2012 Oct;83(10):1213-25. https://doi.org/10.1902/jop.2012.110603

9. Monje A, Alcoforado G, Padial-Molina M, Suarez F, Lin GH, Wang HL. Generalized aggressive periodontitis as a risk factor for dental implant failure: a systematic review and meta-analysis. J Periodontol. 2014 Oct;85(10):1398-407. https://doi.org/10.1902/jop.2014.140135

10. Theodoridis C, Grigoriadis A, Menexes G, Vouros I. Outcomes of implant therapy in patients with a history of aggressive periodontitis. A systematic review and meta-analysis [Review. Erratum in: Clin Oral Investig. 2017 Apr;21] [3]. Clin Oral Investig. 2017 Mar;21(2):485-503. https://doi.org/10.1007/s00784-016-2026-6

11. Mengel R, Flores-de-Jacoby L. Implants in regenerated bone in patients treated for generalized aggressive periodontitis: a prospective longitudinal study. Int J Periodontics Restorative Dent. 2005 Aug;25(4):331-41.

12. Casarin RC, Ribeiro EP, Mariano FS, Nociti Junior FH, Casati MZ, Gonçalves RB. Levels of Aggregatibacter actinomycetemcomitans, Porphyromonas gingivalis, inflammatory cytokines and species-specific immunoglobulin $G$ in generalized aggressive and chronic periodontitis. J Periodontal Res. 2010 Oct;45(5):635-42. https://doi.org/10.1111/j.1600-0765.2010.01278.x

13. Ertugrul AS, Sahin H, Dikilitas A, Alpaslan N, Bozoglan A. Comparison of CCL28, interleukin-8, interleukin-1 $\beta$ and tumor necrosis factor-alpha in subjects with gingivitis, chronic periodontitis and generalized aggressive periodontitis. J Periodontal Res. 2013 Feb;48(1):44-51. https://doi.org/10.1111/j.1600-0765.2012.01500.x

14. Lira-Junior R, Öztürk VÖ, Emingil G, Bostanci N, Boström EA. Salivary and Serum Markers Related to Innate Immunity in Generalized Aggressive Periodontitis. J Periodontol. 2017 Dec;88(12):1339-47. https://doi.org/10.1902/jop.2017.170287

15. Mengel R, Behle M, Flores-de-Jacoby L. Osseointegrated implants in subjects treated for generalized aggressive periodontitis: 10-year results of a prospective, long-term cohort study. J Periodontol. 2007 Dec;78(12):2229-37. https://doi.org/10.1902/jop.2007.070201

16. Lang N, Bartold PM, Cullinan M, Jeffcoat M, Mombelli A, Murakami S, et al. Consensus report: aggressive periodontitis. Ann Periodontol. 1999;4(1):53-53. https://doi.org/10.1902/annals.1999.4.1.53

17. Albandar JM. Aggressive periodontitis: case definition and diagnostic criteria. Periodontol 2000. 2014 Jun;65(1):13-26. https://doi.org/10.1111/prd.12014

18. Conte A, Ghiraldini B, Casarin RC, Casati MZ, Pimentel SP, Cirano FR, et al. Impact of type 2 diabetes on the gene expression of bone-related factors at sites receiving dental implants. Int J Oral Maxillofac Surg. 2015 Oct;44(10):1302-8. https://doi.org/10.1016/i.ijom.2015.06.001

19. Sgolastra F, Petrucci A, Severino M, Gatto R, Monaco A. Periodontitis, implant loss and peri-implantitis. A meta-analysis. Clin Oral Implants Res. 2015 Apr;26(4):e8-16. https://doi.org/10.1111/clr.12319

20. Lieberman JR, Daluiski A, Einhorn TA. The role of growth factors in the repair of bone. Biology and clinical applications. J Bone Joint Surg Am. 2002 Jun;84(6):1032-44. https://doi.org/10.2106/00004623-200206000-00022

21. Leask A, Abraham DJ. TGF-beta signaling and the fibrotic response. FASEB J. 2004 May; 18(7):816-27. https://doi.org/10.1096/fj.03-1273rev

22. Wang R, Xu B, Xu HG. Up-Regulation of TGF- $\beta$ Promotes Tendon-to-Bone Healing after Anterior Cruciate Ligament Reconstruction using Bone Marrow-Derived Mesenchymal Stem Cells through the TGF- $\beta$ /MAPK Signaling Pathway in a New Zealand White Rabbit Model. Cell Physiol Biochem. 2017;41(1):213-26. https://doi.org/10.1159/000456046

23. Kingsley DM. The TGF-beta superfamily: new members, new receptors, and new genetic tests of function in different organisms. Genes Dev. 1994 Jan;8(2):133-46. https://doi.org/10.1101/gad.8.2.133

24. Mundy GR. Regulation of bone formation by bone morphogenetic proteins and other growth factors. Clin Orthop Relat Res. 1996 Mar;324:24-8. https://doi.org/10.1097/00003086-199603000-00004 
Cirano FR, Pimentel SP, Ribeiro FV, Casati MZ, Casarin RC, Gallafassi DF, et al.

25. Merwin JR, Anderson JM, Kocher O, Vanltallie CM, Madri JA. Transforming growthfactorbetal modulatesextra $\neg$ cellularmatrix organizationandcell-celljunctionalcomplex formationduring invitroangiogenesis. J Cell Physiol. 1990 Jan;142(1):117-28.

26. Matarese G, Isola G, Anastasi GP, Favaloro A, Milardi D, Vermiglio G, et al. Immunohistochemical analysis of TGF- $\beta 1$ and VEGF in gingival and periodontal tissues: a role of these biomarkers in the pathogenesis of scleroderma and periodontal disease. Int J Mol Med. Sep;30(3):502-8. https://doi.org/10.3892/ijmm.2012.1024

27. Lee AJ, Hodges S, Eastell R. Measurement of osteocalcin. Ann Clin Biochem. 2000 Jul;37(P† 4):432-46. https://doi.org/10.1177/000456320003700402

28. Baht GS, Hunter GK, Goldberg HA. Bone sialoprotein-collagen interaction promotes hydroxyapatite nucleation. Matrix Biol. 2008 Sep;27(7):600-8. https://doi.org/10.1016/j.matbio.2008.06.004

29. Simonet WS, Lacey DL, Dunstan CR, Kelley M, Chang MS, Lüthy R, et al. Osteoprotegerin: a novel secreted protein involved in the regulation of bone density. Cell. 1997 Apr;89(2):309-19. https://doi.org/10.1016/S0092-8674(00)80209-3

30. Yasuda H, Shima N, Nakagawa N, Yamaguchi K, Kinosaki M, Goto M, et al. A novel molecular mechanism modulating osteoclast differentiation and function. Bone. 1999 Jul;25(1):109-13. https://doi.org/10.1016/S8756-3282(99)00121-0

31. Crotti T, Smith MD, Hirsch R, Soukoulis S, Weedon H, Capone M, et al. Receptor activator NF kappaB ligand (RANKL) and osteoprotegerin (OPG) protein expression in periodontitis. J Periodontal Res. 2003 Aug;38(4):380-7. https://doi.org/10.1034/i.1600-0765.2003.00615.x

32. Wuyts W, Van Wesenbeeck L, Morales-Piga A, Ralston S, Hocking L, Vanhoenacker F, et al. Evaluation of the role of RANK and OPG genes in Paget's disease of bone. Bone. 2001 Jan;28(1):104-7. https://doi.org/10.1016/S8756-3282(00)00411-7

33. Ohmori H, Makita Y, Funamizu M, Hirooka K, Hosoi T, Orimo H, et al. Linkage and association analyses of the osteoprotegerin gene locus with human osteoporosis. J Hum Genet. 2002;47(8):400-6. https://doi.org/10.1007/s100380200058

34. Soedarsono N, Rabello D, Kamei H, Fuma D, Ishihara Y, Suzuki M, et al. Evaluation of RANK/RANKL/OPG gene polymorphisms in aggressive periodontitis. J Periodontal Res. 2006 Oct;41(5):397-404. https://doi.org/10.1111/i.1600-0765.2006.00874.x

35. Garlet GP, Martins W Jr, Fonseca BA, Ferreira BR, Silva JS. Matrix metalloproteinases, their physiological inhibitors and osteoclast factors are differentially regulated by the cytokine profile in human periodontal disease. J Clin Periodontol. 2004 Aug;31(8):671-9. https://doi.org/10.1111/i.1600-051X.2004.00545.x

36. Bostanci N, Ilgenli T, Emingil G, Afacan B, Han B, Töz H, et al. Gingival crevicular fluid levels of RANKL and OPG in periodontal diseases: implications of their relative ratio. J Clin Periodonto. May;34(5):370-6. https://doi.org/ 10.1111/j.1600-051X.2007.01061.x

37. Oliveira RR, Schwartz-Filho HO, Novaes AB, Garlet GP, Souza RF, Taba M, et al. Antimicrobial photodynamic therapy in the non-surgical treatment of aggressive periodontitis: cytokine profile in gingival crevicular fluid, preliminary results. J Periodontol. 2009 Jan;80(1):98105. https://doi.org/10.1902/jop.2009.070465

38. Branco-de-Almeida LS, Cruz-Almeida Y, Gonzalez-Marrero Y, Huang H, Aukhil I, Harrison P, et al. Local and plasma biomarker profiles in localized aggressive periodontitis. JDR Clin Trans Res. 2017 Jul;2(3):258-68. https://doi.org/10.1177/2380084417701898

39. Rutar A, Lang NP, Buser D, Bürgin W, Mombelli A. Retrospective assessment of clinical and microbiological factors affecting periimplant tissue conditions. Clin Oral Implants Res. 2001 Jun;12(3):189-95. https://doi.org/10.1034/i.1600-0501.2001.012003189.x

40. Hodge P, Michalowicz B. Genetic predisposition to periodontitis in children and young adults. Periodontol 2000. 2001;26(1):113-34.

https://doi.org/10.1034/j.1600-0757.2001.2260106.x 